\title{
LOCAL AND REGIONAL ANALGESIA
}

\author{
R. BRYCE-SMITH, D.M., F.F.A.R.C.S. \\ Consultant Anaesthetist, United Oxford Hospitals.
}

THE popularity of local analgesia has waxed and waned more than that of any other anaesthetic technique. It has been employed as an alternative to general anaesthesia to escape the incompetence of the administrator, to avoid the disadvantages of deep narcosis, and to satisfy the needs of the single-handed surgeon. Less commonly it has been considered to confer safety on the patient. This aspect is now stimulating greater interest in spite of a relative abundance of highly trained anaesthetists who can employ specialised and improved techniques with little risk to the patient. Such a swing of opinion will not continue unless it is justified by results and unless the indications are seen in a happier perspective with general anaesthesia. Also, the teaching of local analgesia must be rationalised. Thus many classical procedures, for example, the posterior splanchnic block of Kappis (1919), and Braun's (1905) abdominal inter-muscular block might well be regarded as of academic interest only except in a few special circumstances. The multiplicity of techniques should be reduced-par excellence only one or two of the 26 approaches to the stellate ganglion (Moore, 1954) need be remembered-and many techniques simplified. This however may be too much to expect until it is realised that all forms of local analgesia are dependent on a knowledge of anatomy, both for the course of a nerve and for relating this to reliable landmarks. Above all, the operator must use common sense in applying his knowledge, not only to techniques, but in deciding when local analgesia should be used. The recommendation that a frail patient is fit for local analgesia contains only a grain of truth. Doubtless it is an excellent choice when such a patient requires the excision of a sebaceous cyst, but it is another matter when the operation is to be a partial gastrectomy. Hypotension, paralysis of intercostal muscles and a toxic dose of analgesic drug could follow this extensive procedure and one might even expect the patient to die because of the choice of local analgesia rather than in spite of it.

\section{Drugs}

It is usual to begin any reference to local analgesia with a discussion on the choice of drugs. Since lignocaine is now so widely accepted little can be gained by this. But the introduction of prilocaine is worthy of mention for it claims to increase safety by offering a larger maximum safe dose. (Astrom, 1965). This may be an advantage, but equally, since safety can only be achieved by knowledge and understanding, this virtue may give a false sense of security. Thus the only useful mention of local analgesic drugs at this time is to remind the reader that they are only as safe as the operator who uses them, and understands their properties and dangers. It may be hoped that in the analogy of water dripping on a stone, this simple and fundamental fact will sooner or later make an impression, and thus reduce the number of unnecessary accidents which still occur all too frequently.

Agents used for long-term therapeutic blocks rarely present problems of over-dose, but their efficiency is frequently in question. Solutions of phenol in the subarachnoid space (Maher, 1955) offer a greater chance of success than most methods and have ousted intrathecal alcohol from a position of popularity. On the other hand efficient and reliable blocking of peripheral nerves is completely unsatisfactory. In the author's experience $6 \%$ phenol, oily solutions containing benzyl alcohol, ammonium salts, mucates and alcohol have proved unreliable. Lignocaine with dextran and adrenaline is useful for a few hours, but lignocaine gel (the product of most unwise reasoning) is only mentioned to prevent others causing a mere two hours analgesia followed by a violent herpetiform reaction. Boiling water (Collins, 1960 ) is likely to have more effect on the operator than on the patient. Some success may be expected with $8 \%$ phenol, the highest concentration which solubility permits. But here, the possibility of overdose becomes significant. It is difficult to find factual evidence for a safe dose of phenol by injection. Haxton (1949) 
originally recommended $16 \mathrm{ml}$. of a $6 \%$ solution $(900 \mathrm{mg}$.) for block of the lumbar sympathetic chain. The technique now used (Bryce-Smith, 1955) employs a much smaller volume, but in paravertebral blocks with $8 \%$ solutions, toxic reactions have been seen after the injection of $10 \mathrm{ml}$. (800 mg). It is suggested that not more than 5-6 $\mathrm{ml}$. be injected at any one time since the consequences (respiratory failure and renal damage) are alarming even if not fatal.

Clearly we must await the introduction of some more reliable substance for this purpose, for failures in long-term analgesia represent a serious and urgent deficiency in our abillity to offer pain relief.

\section{Spinal and Extradural Analgesia}

From the mass of published reports it would be possible to provide evidence that spinal analgesia is the method of choice for all surgery: equally easily it could be proved to be so dangerous that it should never be employed. Clearly the truth lies somewhere between these extremes. Opinions have been coloured by the medico-legal consequences of misadventures, culminating in the celebrated case of Woolley and Roe (reported by Cope, 1954). That this tragedy should so influence our views is unfortunate. The incident occurred in 1947 but the case was not actually heard in court until 1953, by which time methods of spinal analgesia, sterilisation and equipment had already undergone extensive revision. It is ironic too, that phenol is now injected deliberately into the subarachnoid space for the relief of intractable pain when the inadvertent seepage of phenol into loral analgesic ampoules was blamed at that time ats the cause of the accident.

Fortunately spinal analgesia still has a few staunch advocates, for its use is reasonable in many situations, and there is now a real difficulty in learning the technique. Although it has been carefully described (Macintosh, 1957) in a monograph which excludes all unnecessary techniques, one is reluctant to advocate a method which cannot be learned from practical experience.

Yet this fear of spinal analgesia has brought about a resurgence of interest in extradural analgesia. This is clearly based on a freedom from untoward consequences, and at the same time an acknowledgement of the merits of local analgesia. Perhaps one of the few serious points of argument lies in the inclusion or otherwise of adrenaline in the injected solution. It is quite contrary to all teaching that large volumes of a strong local analgesic solution should be deposited into a vascular area without the advantage of a vasoconstricting agent to prevent too rapid absorption. Yet this is done commonly in extradural analgesia. The duration of block is not of much interest-continuous methods have overcome this factor-although those who discuss the problem refer to this aspect only to dismiss it. Since there must be a risk of toxic reaction the discussion should centre round the possibility of harm resulting from vasoconstriction. The evidence for this is sketchy, but is based on the belief that if a solution passes through the dura, it can affect the cord, and more particularly, the anterior spinal artery. Thus adrenaline might cause a reduced blood flow, anoxia and hence a cauda equina lesion. Cases have been reported blaming such a sequence, (Davies, Solomon and Levene, 1958) but it is note-worthy that their patient suffered from a degree of hypotension. The original work implicating the passage of drugs across the dura (Frumin, Schwartz, Burns, Brodie and Paper, 1953) suggested that a $2 \%$ solution of procaine deposited in the extradural space led to a concentration of $0.02 \%$ in the cerebrospinal fluid. Applying the same degree of transference to adrenaline, a 1:200,000 solution would become 1:20,000,000 solution in the subarachnoid space. It is hard to imagine that this could have serious vasoconstrictive? properties. Further, the deliberate inclusion of adrenaline to prolong spinal analgesia has been practised without harmful consequences since 1943, (Romberger, 1943). However it is possible that adrenaline could affect the lowest collaterals to enter the anterior spinal artery (at T.11) within the extradural space: but this could only be dangerous if a serious degree of hypotension co-existed which reduced the blood flow in the main artery.

The use of extradural analgesia as an alternative to spinal analgesia is well known, although the choice is often emotional rather than scientific. However the therapeutic applications are not so well appreciated and deserve wider recognition.

\section{Postoperative Pain}

A fow years ago Simpson, Parkhouse, Marshall and Lambrechts (1961) described the use of continuous segmental extradural block for the relief of postoperative pain. This method has received wide acceptance although it is not perhaps original: the term metameric analgesia, implying a segmental block, goes back to the very origins of extradural history (Pages, 1921). Its wider application in the post-

.


operative period is more recent. The intention is to relieve pain by blocking only those segments affected by the operation and thus avoid a fall in blood pressure. If this can be achieved, then the patient may walk, move, cough, and carry out all normal activity without being restricted by the painful splinting of his wound. This is most useful after abdominal and chest operations, but there is no reason why the principle should not also be applied in the postoperative period following any painful operation. A case in point is haemorrhoidectomy, and the degree of discomfort which this procedure entails is rightly feared by all. The local injection of oily solutions, lignocaine in dextran, and in the past, Efocaine, have all been recommended and have their advocates. A continuous caudal, or, on the grounds of cleanliness, lumbar extradural block has much to offer. Theoretically, it may be continued beyond the first one or two bowel movements. In fact, removal of all sensation usually removes the urge to evacuate and constipation results. Nevertheless its employment for the first 48 hours, which should certainly cover the removal of packs or drainage tubes, at least starts recovery on a pain-free basis.

\section{Renal Colic}

During the last year, continuous extradural block has been tried, and is effective, for the relief of the excruciating pain of renal colic. At the same time it is hoped that by relieving the spasm of the ureter, the stone may be passed into the bladder. The somewhat complicated nervous control of the ureter leaves one to doubt such a simple hypothesis, but on the other hand it would appear to be effective in practice. Lloyd and Carrie (1965) reported a small series in which spontaneous passage of the stone occurred in half the cases so treated. This compares favourably with the usually accepted figure of about $30 \%$ in those patients who receive systemic analgesics only. If such results can be substantiated, it is clear that this procedure deserves further attention.

\section{Chest Injuries}

Just as relief of pain after thoracotomy can be relieved by a continuous extradural block, so too can it be of value after chest injuries. Space precludes a full review of the problem but the intention is clearly to relieve pain wihout causing respiratory depression. If this is achieved ventilation will be more effective: active coughing will also become possible and thus reduce the incidence of secondary chest infections and lung collapse. By itself, extra-ڤึ dural block would be indicated where pain 3 is the over-riding problem. This may well be $\stackrel{\varnothing}{\complement}$ in those injuries which are not extensive anato- $C$. mically. and in those patients with pre-existing $\overrightarrow{\overrightarrow{2}}$ respiratory disease associated with excessive secretion, it may be combined with a tracheo- $\frac{C}{0}$ stomy. No useful purpose will be served if $\frac{\bar{\sigma}}{\overline{0}}$ ventilation is inadequate as the result of para- $\frac{\widehat{\sigma}}{\phi}$ doxical respiration in a "flail" chest (Lloyd, $\stackrel{\unrhd}{\varrho}$ Smith and O'Connor, 1965).

\section{Eclampsia}

The introduction of many of the newer $\stackrel{\rho}{\circ}$ anti-hypertensive drugs, used in addition toco heavy sedation, have done much to reduce the 3 . need for more dramatic forms of treatment. $\mathrm{N}$ However in the past a continuous block, whose + main aim was to reduce blood pressure, proved $\infty$ life-saving for some cases of gross edampsia in which a fatal outcome might otherwise have been expected. Lowering of blood pressure stops 은 the headaches and prevents fits. Also, since $\vec{c}$ the load on the heart is relieved, it might be expected to reduce the risk of cardiac failure. Less certain is the relief of vascular spasim $\vec{\oplus}$ in the kidneys which might be a factor in the accompanying oliguria or anuria. For our pus pose, the exact mechanism of the anuria probably unimportant. Suffice it to say that renal "shut-down" has been regarded as an indication for extradural or spinal block in $\frac{\otimes}{\varnothing}$ the past (Hughes, Lovejoy, Lynn, and Hingson, $\stackrel{\Omega}{\vec{B}}$ 1948). Despite the success of this therapy in anuria from other causes, one has the impression that a diuresis is probably coincidental in eclampsia. It is well to remember in this context that eclampsia is a self-limiting disease and improvement usually takes place after delivery. Fluid retention occurs in pregnancy and even the normal parturient has a marked $\delta$ oliguria for 24 hours before delivery. A comparison of the urinary output of patients with 은 eclampsia treated by continuous block and those treated in a more conservative fashion are similar, and indeed the picture is almost the same in a normal labour. Graphs drawn of from patients in these three different groups look almost identical and certainly no dramatic $N_{\omega}$ response can be ascribed to the institution of a continuous block (Bryce-Smith and Williams, 1955).

\section{Peripheral Nerve Blocks}

It is surprising that these have received so little attention, since the greater proportion of 
casualty work relates to the limbs. In view of the recognised dangers of general anaesthesia in an unprepared patient, together with the problems of postoperative care, safety and transport, local analgesia would appear to provide a logical answer. Yet it is viewed with little enthusiasm by accident surgeons who believe that local analgesia interferes with healing and causes spread of infection. This stems from failure to realise that regional blocks can be performed at some distance from the operation site, thus removing objections which quite correctly apply to local infiltration. Some measure of popularity has been accorded supra-clavicular brachial plexus block, but because of the risk of pneumothorax, this technique is being eclipsed by the axillary approach, and the use of intravenous lignocaine. On the other hand, methods of local analgesia for the leg have received scan't attention, partly, one may suppose, because the methods available are not so widely appreciated.

\section{Axillary Block}

The advantages of this technique may be summarised in the words simplicity and safety. The arm is abducted to a right angle and the axillary artery palpated. At the level of the border of pectoralis major the artery lies subcutaneously, almost surrounded by the nerves of the arm. Through a skin wheal. a $3-4 \mathrm{~cm}$. needle is introduced on either side of the artery and $5-10 \mathrm{ml}$ of a local analgesic solution injected. Unless the needle pierces the fibrous neuro-vascular sheath, recognised by a distinct "click", the onset of analgesia may be delayed, (Burnham, 1958).

Many consider that a single injection, provided the needle enters the sheath, is sufficient. A modification suggested by Eriksson and Skarby (1962) almost guarantees this. A tourniquet is placed round the arm at the level of the deltoid insertion during the period of injection. This ensures that the local analgesic surrounds the artery rather than tracking distally down the arm. This has been demonstrated by the injection of radio-opaque solutions. A smaller volume of solution may be used and analgesia develops more rapidly.

The site of insertion of the needle removes all risk of damage to the pleura, though at the same time it limits the area of analgesia to the forearm and elbow. Thus a classical supraclavicular approach is still required if it is necessary to provide analgesia of the shoulder region.

\section{Intravenous Analgesia}

This technique, remodelled on that described by Bier in 1905, requires no skill other than the ability to insert a needle into a vein (Holmes, 1963). However, attention to certain details is essential for success and the avoidance of toxic reactions. After inserting a Mitchell or Gordh needle into a vein on the dorsum of the hand, a sphygmomanometer cuff is placed as high as possible on the upper arm. The limb is exsanguinated, preferably by use of an Esmarch bandage, but if this is impossible owing to pain or the risk of further injury, elevation of the limb is a satisfactory alternative. The sphygmomanometer cuff is now inflated to above the level of the systolic pressure, and $30-40 \mathrm{ml}$. of $0.5 \%$ lignocaine or prilocaine injected through the needle. Analgesia develops rapidly and will persist until the tourniquet is released. To obviate pain from the sphygmomanometer cuff, a second cuff may be applied at a lower level over an area already rendered analgesic by the injection. Untoward reactions will occur if the cuff is released within 10 minutes of the injection, and recently it has been suggested (Kennedy, Duthie, Parbrook and Carr, 1965) that these may also occur much later. Fainting. dizziness and the cardiac arrhythmias reported can hardly be dismissed, but it is surprising that so many other workers have testified to the safety of the method and its lack of sequelae (Sorbie and Chacha, 1965; van Niekerk and Tonkin, 1966). Although this has been attributed to an interrupted release of the tourniquet, (Merrifield and Carter, 1965) this suggestion has not been widely used although it was one of Holmes' original recommendations. Surprising, too, are the divergent blood levels of lignocaine that have been reported (Table 1), and in consequence the figures regarded as "safe". Possibly one may assume that these differences can be accounted for by the different techniques and sampling methods used. Certainly the last word on this problem has not yet been written.

Intravenous analgesia of the lower limb is less satisfactory. A greater bulk of tissue makes the application of sphygmomanometer cuff to the thigh difficult: the larger volume of solution necessary $(80-100 \mathrm{ml}$.) is likely to have much more serious consequences should the cuff slip: and venepuncture on the feet, which more often than not are cold and vasoconstricted, is far from easy. Nevertheless the method is effective but possibly not justified when a simpler block would do as well. 
TABLE 1

Bell, Slater, and Harris
(1963)

Dose
$1.5 \mathrm{mg} / \mathrm{kg}$
$3.0 \mathrm{mg} / \mathrm{kg}$

Blood Level

$0.7 \mu \mathrm{g} / \mathrm{ml}$

Merrifield and Carter

(1965)

Hargrove, Hoyle, Parker,

Beckett and Boyes,

(1966)

$4 \mathrm{mg} / \mathrm{kg} \quad 6.0 \mu \mathrm{g} / \mathrm{ml}$

The variation in blood levels of lignocaine recorded by different workers when using intravenous regional analgesia. Bromage and Robson (1961) accept 10 $\mu \mathrm{g} / \mathrm{ml}$. as the maximum blood level which will not cause toxic reactions, though Foldes, Molloy, MoNall, and Koukal (1950) considered that this figure should be no more than $5.5 \mu \mathrm{g} / \mathrm{ml}$.

In trying to overcome the hazard which may result from the intravenous injection of such a quantity of local analgesia, there has been a revival of interest in intra-arterial regional analgesia (van Niekerk and Coetzee, 1965). The technique, first described by Goyanes in 1908 is similar to that of the intravenous method, but requires an injection of about $14 \mathrm{ml}$. of $0.5 \%$ solution into an artery, usually the brachial at the elbow. Difficulties in the leg were even greater than in the intravenous method. The authors, who have an extensive experience of both intra-arterial and intravenous techniques suggest that the former is only suitable for the expert in intra-arterial puncture and is not to be recommended for general use.

\section{Median Plantar Nerve}

An example of a simple, reliable block in the leg which is safer than intravenous analgesia is that of the median plantar nerve. A needle is inserted through a point midway between the medial malleolus and the tendo Achilles. Angled $30^{\circ}$ anteriorly (i.e., at right angles to the skin rather than the plane of the leg) it will then strike the posterior aspect of the talus or tibia. An injection of $5 \mathrm{ml}$. of solution will block the nerve as it winds beneath the malleolus before spreading out to supply the greater part of the sole of the foot. No other structures can be damaged by the needle and since the anatomical space into which the injection is made is limited, failure is almost unknown. This technique deserves a much wider recognition and should certainly replace the barbaric practice of infiltration of the sole of the foot, which, because it causes such exquisite pain, is likely to be performed inadequately. If any proof is needed of the efficacy of this block it should be tried on a patient who is to have diathermy applied to a verruca on the sole.
This apparently simple surgical procedure has humiliated many anaesthetists administering az general anaesthetic: the depth of anaesthesia $\stackrel{\varnothing}{\AA}$ required to overcome such intense stimulation $C$ almost exceeds what might be considered ac- $\overrightarrow{\vec{s}}$ ceptable for an outpatient procedure.

To complete a local analgesic block of the foot two further procedures are required. These $\overline{\bar{c}}$. are block of the lateral peroneal nerve, best $\frac{\pi}{\sigma}$ performed as it winds round the neck of the $\varnothing$ fibula, and a superficial infiltration over the anterior aspect of the ankle from medial to $\overrightarrow{0}$ lateral malleolus. In almost all respects these $\vec{\overrightarrow{ }}$ procedures correspond to those performed for $\vec{\omega}$ block of the wrist. The median plantar nerve represents the median nerve, the superficial infiltration corresponds to that done to anaesthetise the superficial branches of the radial nerve, and injection of the lateral peroneal nerve is equivalent to blocking the ulnar nerve at the elbow. In a true wrist block the ulnar $\underset{\checkmark}{\checkmark}$ nerve can be reached as it lies medial to the 을 pisiform bone, but it is more easily palpated at the elbow. But when nerves lie superficially in relation to a bone, and hence are in vulnerable positions - the ulnar and lateral peroneal nerves are good examples of this-they are usually protected by a tough, fibrous sheath Thus a local analgesic solution deposited oute side the sheath will take anything up to $20-3 \hat{\theta}^{+}$ minutes to produce complete analgesia, although when the sheath is pierced analgesia will develop almost immediately.

A warning however must be sounded for those who perform a block of the lateral peroneal nerve. The anaesthetist who regards it as a purely sensory nerve to the lateral border of the foot may forget that it also supplies the flexor muscles of the ankle, and analgesia will therefore produce a foot drop at the same time. Unless a patient is warned of this he is likely to trip and receive more serious injuries.

There is no single peripheral nerve block of the lower limb corresponding to brachial or axillary block in the arm. Thus blocks of individual nerves must be carried out and although these present no great technical difficulty, it becomes necessary to turn the patient in order to reach the sciatic nerve. Certainly anterior (Beck, 1963) and lateral (Ichiyanagi, 1959) approaches to this nerve have been described which allow the patient to remain supine, but in the author's experience these have proved to be less reliable than the more usual posterior approach. Of the obturator, femoral and sciatic nerve blocks which are necessary to provide analgesia of the whole of the lower limb, only 
the latter has been used at all frequently, and then more for therapeutic than surgical purposes.

\section{Sciatic Nerve Block}

In the classical description, a line is drawn between the greater trochanter and the posterior superior iliac spine, from whose midpoint a perpendicular is dropped for a distance of $3 \mathrm{~cm}$. (Labat, 1922). A needle inserted at this point will strike the nerve as it crosses the ischial spine. Alternatively, one may draw a line between the greater trochanter and the ischial tuberosity and take the junction of the middle and inner thirds as the point at which the needle is inserted. A simpler description, and one which causes the needle to be inserted at exactly the same point, is to bisect the line between the greater trochanter and the sacral hiatus.

\section{Landmarks}

Reference to the land marks for sciatic nerve block may be used as an example of the need to reconsider many of the classical descriptions. All too often these include the drawing of imaginary lines, dropping perpendiculars, and in the location of many arbitrary points. It should not be forgotten that local analgesia is likely to succeed only if the needle can be inserted in relation to accurate landmarks. Bony landmarks are the most reliable and for preference these should be palpable. These points are demonstrated in descriptions of cervical plexus block. Again, classically, a line is drawn between the mastoid process and Chassaignac's tubercle which is then divided into five equal parts. The middle three points now represent the lateral tips of the transverse processes of the second, third and fourth cervical vertebrae. However, palpation of the neck from in front will reveal that these points can be palpated easily: and the level can be determined by reference to the greater cornu of the hyoid bone which lies opposite C3. Thus a more modern description of cervical plexus block (Macintosh and Ostlere, 1955) advises an anterior approach with the needle inserted while the transverse process is palpated directly with the finger.

Further thought will show that a similar application of basic anatomy and common sense will make many nerve blocks in different parts of the body more logical. One may then dispense with the need to remember parrot-wise a complicated description, probably only half remembered from some major reference book.
The author is conscious of a failure to apply such common sense in describing the technique for an inguinal hernia block (Macintosh and Bryce-Smith, 1962). Here the operator is advised to block the ilio-inguinal and ilio-hypogastric nerves at a point related to the anterior superior spine; to infiltrate towards the rib margin to anaesthetise the lateral branches of the 11th and 12th intercostal nerves; and to infiltrate the mid-line to prevent overlap from the opposite side. Such a procedure involves the deposition of some $30-40 \mathrm{ml}$. of solution. The purpose of all this is simply to render the skin incision painless. Yet a subcutaneous infiltration in the line of the incision would involve no more than $10 \mathrm{ml}$. of solution and would be more effective. Infiltration in the region of the internal ring must still be done, but by simplifying the first part of the procedure, time and much local analgesic solution is saved. Other examples of unnecessarily complicated techniques exist, and more have probably not yet been recognised. The thoughtful operator will appreciate these when he follows a sound rational method rather than relying on a theoretical description.

Many nerve blocks cannot be simplified as easily as the examples given but in all cases satisfactory results can only be achieved by repeated practical experience. It should also be realised that even if some of the more complicated procedures no longer seem to have any regular place in anaesthetic practice, attention to many of the simpler nerve blocks which can be performed rapidly, safely and effectively would be rewarded by the satisfaction of patients and surgeons alike.

\section{REFERENCES}

Astrom, A. (1965): Some Pharmacological Properties Determining Action and Toxioity of Local Anzesthetics, Proc. roy. Soc. Med., 58, 415.

BECK, G. P. (1963): Anterior Approach to Sciatic Nerve Block, Anesthesiology, 24, 222.

Bell, H. M., Slater, E. M. E., and Harris, W. H. (1963): Regional Anesthesia with Intravenous Lidocaine, J. Amer. med. Ass., 186, 98.

BIER, A. (1908): Ueber einen neuen Weg Lokalanesthie an der Gliedmassen zu Erzeugen, Arch. Klin. Chir., 86, 1007.

Braun, H. (1905): Die Lokalanesthesie. p. 3111. Liepzig.

Bromage, P. R., and Robson, J. G. (1961): Concentrations of Lignocaine in the Blood after Intravenous, Intramuscular, Epidural and Endotracheal Administration, Anaesthesia, 10, 461.

BRYCE-SMITH, R. (1955): Chemical Sympathectomy, Anaesthesia, 10, 173.

BRYCE-SMITH, R. and Williams, E. O. (1955): The Treatment of Eclampsia by Continuous Conduction Analgesia, Lancet, i, 1241. 
BurnhaM, R. J. (1958): Regional Block of the Great Nerves of the Upper Arm, Anesthesiology, 19, 281.

Collins, V. J. (1960): Fundamentals of Nerve Blocking. London: Henry Kimpton.

Cope, R. W. (1954): The Woolley and Roe Case, Anaesthesia, 9, 249.

Davies, A., Solomon, B., and Levene, A. (1958): Panaplegia following Epidural Anaesthesia, Brit. med. J., ii, 654.

EriksSON, E., and Skarby, H. G. (1962): A Modified Method for Axillary Plexus Anaesthesia, Nord. Med., 68, 1325

Foldes, F. F., Molloy, R., McNall, P. G., and Koukal, L. R. (1960): Comparison of Toxicity of Intravenously given Local Anesthetic Agent in Man, J. Amer. med. Ass., 172, 1493.

Frumin, M. J., Schwartz, H., Burns, J. J., Brodie, B.B., and PAPPER, E. M. (1953): The Appearance of Procaine in the Spinal Fluid during Peridural Block in Man, J. Pharmacol. exp. Ther., 109, 102.

Goyanes, J. (1912): La Anestesia por la Via Arterial, Rev. Clin. de Madrid, 8, 401.

Hargrove, R. L., Hoyle, J. R., Parker, J. B. R., BECKETT, H. A. H., and BOYES, R. N. (1966): Blood Lignocaine Levels following Intravenous Analgesia, Anaesthesia, 21, 37.

Haxton, H. A. (1949): Chemical Sympathectomy, Brit. med. J., i, 1206.

Holmes, C. MoK. (1963): Intravenous Regional Analgesia, Lancet, i, 245.

HugheS, J. G., Lovejoy, J. S., LYNN, H. D., and Hingson, R. A. (1948): Use of Continuous Caudal Analgesia for Control of Hypertension in Acute Nephritis, Amer. J. Dis. Child., 75, 291.

ICHIYANAGI, K. (1959): Sciatic Nerve Block: Lateral Approach with the Patient Supine, Anesthesiology, 20, 61 .

KAPPIS, M. (1919): Sensibilität und Lokale Anästhesie im Chirurgischen Gebiet der Bauchhöhle mit besonderer Bërucksichtigung der Splanchnicusanästhesie, Beitre. klin. Chir., Tübing., 115, 161.

Kennedy, B. R., Duthie, A. M., PARBroOK, G. D. and CARR, T. L. (1965): Intravenous Regional Analgesia: An Appraisal, Brit. med. J., i, 954.
Labat, G. (1922): Regional Anesthesia. p. 289 Philadelphia: J. B. Lippincott.

Lloyd, J. W., and CARrie, L. E. S. (1965): A Methodo of Treating Renal Colic, Proc. roy. Soc. Med., 58, 634.

Lloyd, J. W., Smith, A. C. and O'ConNor, B. T: (1965): Classification of Chest Injuries as an Aid to Treatment, Brit. med. J., i, 1518 .

Macintosh, R. R. (1957): Lumbar Puncture andō Spinal Analgesia. Edinburgh and London: E. \& S $\overline{\bar{\sigma}}$ Livingstone.

MACINTOSH, R. R. and BRYCE-SMith, R. (1962): Loca尺 Analgesia: Abdominal Surgery. 2nd Edition. pp پֶ 68-71. Edinburgh and London: E. \& S. Livingstone-

Macintosh, R. R. and Ostlere, M. (1955): Local. Analgesia: Head and Neck. p. 101. Edinburgh and London: E. \& S. Livingstone.

MAHER, R. M. (1955): IRelief of Pain in Incurables Cases, Lancet, i, 18.

Merrifield, A. J. and CARTER, S. J. (1965): Intraven-3. ous Regional Analgesia: Lignocaine Blood Levels, ?
Anaesthesia, 20, 287.

MOORE, D. C. (1954): Stellate Ganglion Block.. Springfield, Illinois: Charles C. Thomas.

PAGES, F. (1921): Anastesia Metamerica, Rev. de San. Militar, ii, 351.

Romberger, F. T. (1943): Spinal Anesthesia-Prac-음 tical Facts and Common Fallacies-Clinical Re- search on Prolonged Spinal Anesthesia usinge Vasoconstriction Adjunctives, Anesth. and Analg.,, 252 .
22,

Simpson, B. R., Parkhouse, J., Marshall, R. agd $\overrightarrow{0}$ LAMBRECHITS, W. (1961): Extradural Analgesia aqdo the Prevention of Postoperative Respiratory Com plications, Brit. J. Anaesth., 33, 628.

Sorbie, C. and Chacha, P. (1965): Regional Ana thesia by the Intravenous Route, Brit. med. J., i, 957.

VAN Niekerk, J. P. DE V. and Coetzee, T. (1965): Intra-arterial Regional Analgesia, Lancet, i, 1353.

VAN NiEkERK, J. P. DE V. and TONKIN, P. A. (1966): $\overrightarrow{\vec{a}}$ Intravenous Regional Analgesia, S. Afr. med. J. In press. 